\title{
Research on improving water quality using two experimental statistical methods
}

\author{
Mihail Aurel Țîțu, ${ }^{1, *}$, Andrei Victor Sandu², Costel Ceocea ${ }^{3}$, Alina Bianca Pop ${ }^{4}$, Ștefan Țițu ${ }^{5}$ \\ and Alexandra Maria Matia ${ }^{6}$ \\ 1 "Lucian Blaga" University of Sibiu, 10, Victoriei Street, code 550024, Sibiu, România \\ 2 "Gheorghe Asachi" Technical University of Iasi, Romanian Inventors Forum, 59A, Mangeron \\ Street, code 700050, Iasi, Romania \\ ${ }^{3}$ SIF MOLDOVA Bacău, 94C, Pictor Aman Street, code 600164, Bacău, Romania \\ ${ }^{4}$ SC TechnoCAD SA, 72, Vasile Alecsandri Street, code 430351, Baia Mare, Romania \\ ${ }^{5}$ The Oncology Institute "Prof. Dr. Ion Chiricuță", 34-36, Republicii Street, Cluj Napoca, România \\ ${ }^{6}$ SC Computer Generated Solutions SRL Sibiu, Gate 2, Hidrosib Complex, 193, Ștefan cel Mare \\ Street, code 550316, Sibiu, Romania
}

\begin{abstract}
This scientific paper addresses the importance of water treatment process until it becomes drinkable, studying the treatment process from different points of view that are considered to be relevant. The choice of this subject was motivated by the water consumption importance for the entire population, the scientific paper proposing to study in what way this water treatment process could be improved, using for analysis two methods of experimental statistical modeling, namely the Taguchi's method and the factorial experiment method. The purpose of this scientific paper was to identify the deficiencies of the water treatment process after it entered the treatment plant and analyze is carried out using the two mentioned methods above, were continued by finding optimization solutions for the process. These solutions are intended to avoid the situations in which the treatment plant may be unable to cover the required volume of drinking water and to ensure the quality of the drinking water supplied to consumers according to the legislation to date. The knowledge benefit of this research consists in the realization of the research intentions formulated and the practical applicability of the results.
\end{abstract}

\section{Introduction}

Water is the most widespread mineral substance on the earth's surface and plays a key role in the socio-economic development of a nation [1]. This research shows the water importance from a global perspective, the purposes multitude in which it is used, its features and properties continuing with people's dependence on water drinking and the dangers it can pose if it reaches consumers without being treated properly. Without water, all of the biological reactions would become impossible, so it is stated, not without reason, that man, like all living creatures, lives in water or is constantly bathed by water. This affirmation is reinforced by the fact that adult water accounts for $60 \%$ of its entire body weight [2]. On 28 July 2010 ,

*Corresponding author: mihail.titu@ulbsibiu.ro 
the General Assembly of the United Nations explicitly recognized through Resolution 64/292 that access to drinking water and sanitation represents human rights and also acknowledged that drinking water and sanitation are essential to the fulfilment of all human rights [3], [4].

\section{Research methodology}

\subsection{Experimental methods}

In order to help the treatment plan to improve the quality of the water treatment process were applied two experimental statistical modeling methods: Taguchi's method and factorial experiment method. Taguchi focuses especially on the design phase, considering it is more economical to make a process insensitive to variations than to take corrective action [5]. The major contribution that G. Taguchi brings through his method consists in combining the engineering techniques he possesses with the statistical techniques in order to obtain a fast improvement in quality costs, seeking optimization at the level of product design and manufacturing processes [6]. The philosophy of Taguchi's method of product quality optimizing is synthesized by three basic concepts [7]: quality must be projected into the product and not inspected in the product after it has been manufactured; the highest value of quality is obtained when the deviation from the proposed target is minimal, or when the action of uncontrollable factors has no influence on it, which translates into robustness; the costs associated with quality are expressed as a function of the deviation from the nominal value. Regarding the second method, in statistics, a full factorial experiment is an experiment whose project consists of two or more factors, each with discrete values/levels, and whose experimental units take up all possible combinations of these levels for all of these factors.

\subsection{Taguchi's method}

The philosophy of a Taguchi experimental plan is to reduce the variance of the process dependent variables by finding experimental conditions in which the uncontrolled variation of process factors have a minimal impact on the product quality. When using the Taguchi experimental plan, a distinction is made between the experimental factors and the background noise factors $[7,8]$. Taguchi focuses especially on the design phase, considering that it is more economical to make an insensitive process of variation than to carry out corrective actions. He disagrees with the "zero defects" objective because he claims (rightly) that there will always be uncontrollable random factors that can cause problems - be they minor [8]. In the process of obtaining drinking water, it is frequently encounter the presence of organic or inorganic water particles that are in suspension and do not sediment over time and which reduce the water transparency, caused by the undissolved materials presence, in other words, the presence of solid particles in water. The level of these particles was confronted with the level of organic substances in the raw water which must be permanently monitored. The arisen problems during the water treatment process have led to this decision, to apply this method and to measure its effectiveness. The steps of the drinking process with the related goals and deficiencies are: - capture of surface water with the purpose of decanters supply with raw water, in this case the amount of water entering the decanter may be insufficient or too high and the number of decanters reduced; - decanting - with the turbidity decrease and organic matter by at least $25 \%$ and the need for longer settling time in order to be able to lower the parameter values; - filtering - turbidity and organic matter values should drop by more than $25 \%$, decrease to as much as $50 \%$ having a flow rate of water flow; chlorination - for potable water there must be a residual minimum chlorine concentration of $0.1 \% \mathrm{mg} / \mathrm{l}$, the deficiency is the failure to observe the working instructions, unwanted 
products such as chlorohydrocarbons can be generated, especially in organically contaminated water, and the bacterial contamination by excess chlorine is often exaggerated because the chlorine concentration is exhausted quickly. For the experiment, four factors with two control levels, were chosen, namely (Table 1): Capturing surface water: following the amount of water entering the decanter; decanting: following the water settling time; filtration: following the flow rate of water flow; chlorination: following the amount of chlorine added to the water so as to obtain potable water at the outlet of the station. The defects encountered cannot be quantified in a continuous way and are treated as qualitative criteria.

Table 1. Factors and levels of control.

\begin{tabular}{|c|c|c|c|}
\hline No. & Controlled factor & Level 1 (minimum) & Level 2 (maximum) \\
A & $\begin{array}{c}\text { Capture of Surface } \\
\text { Water }\end{array}$ & $\begin{array}{c}\text { It can be reduced to 0 (the } \\
\text { decanters will be closed at a } \\
\text { very high flow rate) }\end{array}$ & $300 / 400 \mathrm{~m}^{3} / \mathrm{h}$ \\
\hline B & Decanting & $24 \mathrm{~h}$ & $48 \mathrm{~h}$ \\
\hline C & Filtering & $80 \mathrm{~m}^{3} / \mathrm{h}$ & $200 \mathrm{~m}^{3} / \mathrm{h}$ \\
\hline D & Chlorination & $\begin{array}{c}0 \mathrm{mg} / 1-\text { Indicated is to be } 0.1 \\
\text { milligram of chlorine per liter } \\
\text { of water }\end{array}$ & $\begin{array}{c}500-\text { Indicated is to be } 0.5 \\
\text { milligram of chlorine per liter of } \\
\text { water }\end{array}$ \\
\hline
\end{tabular}

The quality criteria pursued - being divided into two groups as follows: I. Turbidity of water; Criterion to be minimized; II. Organic substances; Criterion to be minimized. Next, the two types of $\mathrm{S} / \mathrm{N}$ ratio results in $\mathrm{dB}$, will be compared in Figure 1 and Figure 2. For each factor, the highest $\mathrm{S} / \mathrm{N}$ ratio should be selected. It can be seen that the four factors $\mathrm{A}, \mathrm{B}, \mathrm{C}$, $\mathrm{D}$ used in the experiment do not produce conflicts of influence between the two quality criteria that need to be optimized. The results obtained in the validation test are very close to the ones expected, the better values than expected, were obtained. The $\mathrm{S} / \mathrm{N}$ ratio value is inferior then the theoretically $\mathrm{S} / \mathrm{N}$ ratio resulting in $\mathrm{dB}$ in the first optimization test and is higher than the measured theoretically measured value for the qualitative criterion I Turbidity. And for the qualitative criterion II - Organic Substances, the value of the $\mathrm{S} / \mathrm{N}$ ratio is inferior to the theoretically $\mathrm{S} / \mathrm{N}$ ratio resulting in $\mathrm{dB}$ in the first optimization test and is lower than the theoretically measured value. To achieve the desired results at the end of the water drinking process, to implement the following solutions, were chosen: the flow of surface water to be captured in the two radial horizontal decanters will be monitored to fall within the range of $300-400 \mathrm{~m}^{3} / \mathrm{h}$ to avoid the entry of too much raw water containing a highvolume turbidity and organic substances, especially during periods of heavy rainfall.

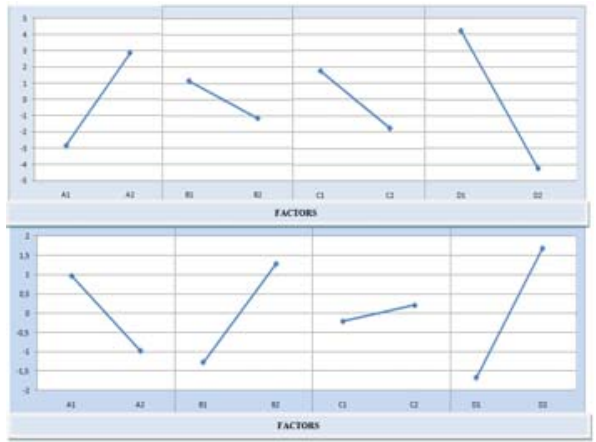

Fig. 1. Charts for Effects of Factors and Interactions - Criterion I.

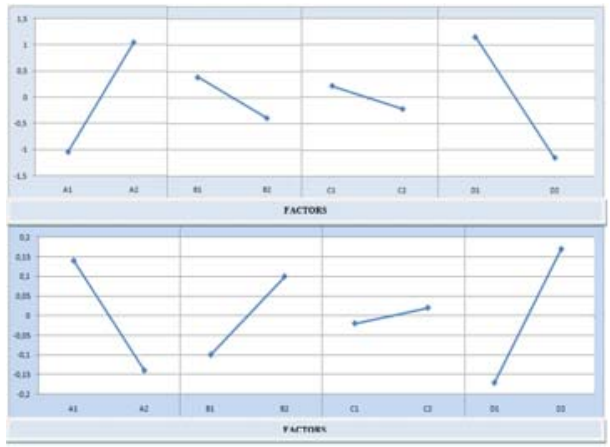

Fig. 2. Charts for Effects of Factors and Interactions - Criterion II. 
The time that the water will be in the decantation must always be at least $24 \mathrm{~h}$, increasing this period as needed. 4 to 6 quick filters, consisting of quartz sand concrete tanks to filter the water with $80 \mathrm{~m}^{3} / \mathrm{h}$. For chlorination the ADVANCE gaseous chlorine dispenser, pumping $0.1 \mathrm{mg} / \mathrm{l}$, will be used. After the raw water passes all the stages of the process required by the trawler to obtain the desired values and the parameters we analyze meet the requirements of the quality criteria, the water can be sent for storage to the two semi-buried concrete tanks, from where through the adduction pipes will reach consumers. As can be seen from the presented experiment, Taguchi's method has been of great help in solving a process optimization problem, in this case the process of obtaining drinking water by defining the objective must be attained, that is to say the quality characteristics to be optimized; determining the factors that influence the process and its levels; choosing the matrix of experiences to use; performing the tests and measuring the results; processing the results and calculating the effects of the tested factors; choosing the optimal configuration of the levels of the tested factors and, last but not least, making a validation attempt that confirms that these solutions can be adopted because they are optimal.

\subsection{The factorial experiment}

Table 2. Samples of water taken.

\begin{tabular}{|c|c|c|c|c|c|c|}
\hline No. & $\begin{array}{c}\text { as } \\
\left(\mathbf{m}^{\mathbf{3}} / \mathbf{h}\right)\end{array}$ & $\begin{array}{c}\mathbf{d} \\
\mathbf{( h )}\end{array}$ & $\begin{array}{c}\mathbf{f} \\
\left(\mathbf{m}^{\mathbf{3}} / \mathbf{h}\right)\end{array}$ & $\begin{array}{c}\mathbf{c} \\
(\mathbf{m g} / \mathbf{l})\end{array}$ & $\begin{array}{c}\mathbf{T} \\
(\mathbf{n t u})\end{array}$ & $\begin{array}{c}\mathbf{S O} \\
(\mathbf{m g} / \mathbf{l})\end{array}$ \\
\hline 1 & 340 & 35 & 340 & 170 & 5,13 & 1,59 \\
\hline 2 & 340 & 40 & 340 & 170 & 3,88 & 1,52 \\
\hline 3 & 340 & 42 & 340 & 170 & 2,44 & 1,32 \\
\hline 4 & 340 & 48 & 340 & 170 & 0,41 & 0,26 \\
\hline 5 & 370 & 24 & 370 & 185 & 8,63 & 1,74 \\
\hline 6 & 370 & 35 & 370 & 185 & 5,22 & 1,49 \\
\hline 7 & 370 & 48 & 370 & 185 & 0,94 & 0,78 \\
\hline 8 & 370 & 48 & 370 & 185 & 0,92 & 0,64 \\
\hline 9 & 400 & 24 & 400 & 200 & 18,06 & 2,75 \\
\hline 10 & 400 & 24 & 400 & 200 & 11,37 & 2,08 \\
\hline 11 & 400 & 30 & 400 & 200 & 6,14 & 1,59 \\
\hline 12 & 400 & 40 & 400 & 200 & 3,10 & 0,98 \\
\hline 13 & 390 & 24 & 390 & 195 & 7,94 & 1,71 \\
\hline 14 & 390 & 30 & 390 & 195 & 6,52 & 1,63 \\
\hline 15 & 390 & 40 & 390 & 195 & 3,64 & 1,41 \\
\hline 16 & 390 & 40 & 390 & 195 & 3,01 & 1,39 \\
\hline 17 & 348 & 35 & 348 & 174 & 5,66 & 1,57 \\
\hline 18 & 348 & 38 & 348 & 174 & 4,54 & 1,49 \\
\hline 19 & 348 & 42 & 348 & 174 & 2,49 & 1,33 \\
\hline 20 & 348 & 42 & 348 & 174 & 2,20 & 1,01 \\
\hline 21 & 300 & 40 & 300 & 150 & 3,93 & 1,56 \\
\hline 22 & 300 & 42 & 300 & 150 & 2,68 & 1,34 \\
\hline 23 & 300 & 48 & 300 & 150 & 0,97 & 0,68 \\
\hline 24 & 300 & 45 & 300 & 150 & 1,33 & 0,70 \\
\hline 25 & 280 & 45 & 280 & 140 & 1,34 & 1,09 \\
\hline 26 & 280 & 45 & 280 & 140 & 1,05 & 0,98 \\
\hline 27 & 280 & 48 & 280 & 140 & 0,29 & 0,36 \\
\hline 28 & 280 & 48 & 280 & 140 & 0,38 & 0,39 \\
\hline 29 & 400 & 24 & 400 & 200 & 9,95 & 1,95 \\
\hline 30 & 400 & 30 & 400 & 200 & 6,14 & 1,59 \\
\hline 31 & 400 & 35 & 400 & 200 & 5,14 & 1,58 \\
\hline & & & & & & \\
\hline
\end{tabular}

Like in Taguchi's method case, in this experiment the same four factors at two levels of control, were chosen.

The four variable functions are presented with their names that will serve as input data, as well as the two objective functions with the corresponding names that will serve as exit data. The input data are: As Capture of Surface Water $\left(\mathrm{m}^{3} / \mathrm{h}\right)$; D - Decanting (h); F - Filtration $\left(\mathrm{m}^{3} / \mathrm{h}\right)$; $\mathrm{C}$ - Chlorination (mg/l). The output data are: SO - Organic Substances $(\mathrm{mg} / \mathrm{l})$ Turbidity (NTU = Neophelometric Turbidity Unit). For the construction of Table 2, water samples were taken to pass it through the different treatment steps over one month.

It is possible to observe the turbidity and organic matter values after passing through all stages of treatment, namely the water entering volume, the water station, the water settling time, the volume of water that has been filtered and the total amount of chlorine added to the water. In Figure 3 is graphically represented by the function of the turbidity lens being influenced by the volume of water entering the station and its decanting time. 
An increase of the turbidity is observed with decreasing water settling time and an increase of the turbidity with the entry of a large volume of water into the storage basins. The maximum turbidity value in this case is 12 and the minimum value is $0,291 \mathrm{ntu}$, depending on the volume of the surface water and the decanting time. The highest recorded turbidity value corresponds to $22 \mathrm{~h}$ (decanting time) and $420 \mathrm{~m}^{3}$ (capture of surface water volume), respectively.

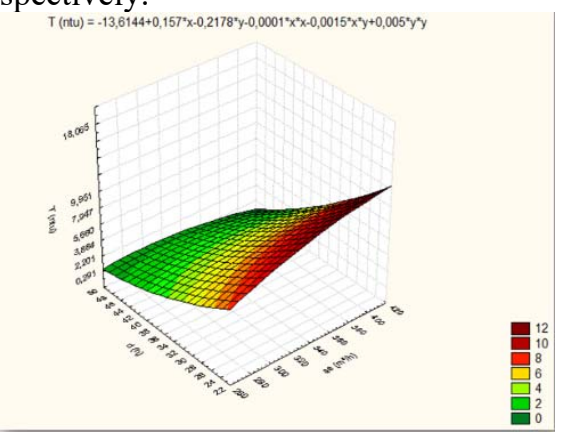

Fig. 3. Graphical representation of turbidity based on capture of surface water volume and decanting time using the 3D Surface Plot function.

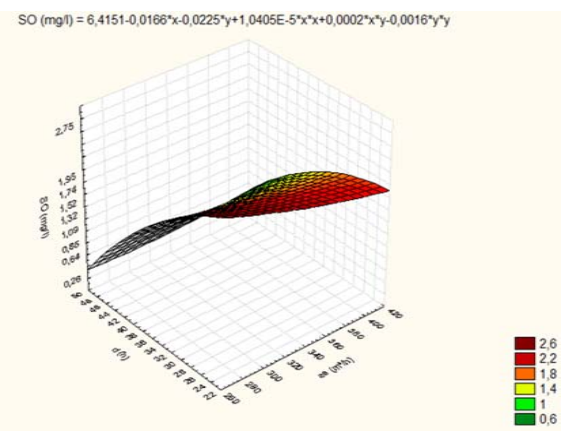

Fig. 4. Graphical representation of organic substances based on capture of surface water volume and decanting time using the $3 \mathrm{D}$ Surface Plot function.

In Figure 4 it can be seen a graphical representation of the objective function of organic substances, being influenced by the volume of water entering the station and its decanting time. There is an increase in the values of organic substances as the water decanting time decreases and the volume of captured surface water entering the storage tanks decreases. The maximum value of organic substances is $2.6 \mathrm{mg} / \mathrm{l}$ and the minimum value of $0.6 \mathrm{mg} / \mathrm{l}$, depending on the captured surface water volume and the decanting time. The highest value recorded by organic substances corresponds to $22 \mathrm{~h}$ (decanting time) for different levels of the volume of surface water entering the basins, ranging from $220 \mathrm{~m}^{3}$ to $300 \mathrm{~m}^{3}$. Considering all the data presented, it can be seen that the highest values of turbidity and organic substances in the water are found significantly in the periods when more rainfall occurs. At the same time, an increase in turbidity and organic matter is observed with the water settling time decreasing and an increase of the same with the entering of a large volume of water in the accumulation basins. In the both cases, the turbidity and the organic substances, the highest value recorded by them corresponded to $22 \mathrm{~h}$ decantation time, hence it can be deduced that as the decanting process lasts longer the level of turbidity and organic substances in water decreases. Analysing the graphs resulting from the comparison of the two objective functions according to the volume of filtered water and the decanter time, it results that as the decanting process lasts longer, the level of turbidity and organic matter in the water decreases, the volume of filtered water does not significantly affect their values, although it can be seen that the two objective functions are inversely influenced by the volume of water that is filtered, since the turbidity values increase to a large volume of filtered water and the organic substance values decrease to the filtration of a high water volume. About the experiment results, it can be seen how the amount of added chlorine is closely related to the water settling time. Also, following the experimental results research, the both turbidity and organic matter record the highest value at a surface water volume of $400 \mathrm{~m}^{3} / \mathrm{h}$ at a very low settling time, i.e. less than $24 \mathrm{~h}$, at a volume of filtered water of $400 \mathrm{~m}^{3} / \mathrm{h}$ and an amount of $200 \mathrm{mg}$ of added chlorine. In conclusion, the further monitoring of the parameters and their fitting into the optimum limits imposed above, namely the volume of surface water entering does not exceed $400 \mathrm{~m}^{3} / \mathrm{h}$, the water settling time is at least $24 \mathrm{~h}$, and as much as possible maximization depending on the necessity at that time, the volume of 
filtered water does not exceed $400 \mathrm{~m}^{3} / \mathrm{h}$ and the amount of chlorine added is not more than $200 \mathrm{mg}$, it will lead to continuous improvement of the process.

\section{Conclusion}

It is extremely important to have information on the quality of drinking water supplied to consumers and the latter to have access to the tests carried out by the drinking water analyzes laboratories because we must not forget that the water that is supplied through the distribution networks represents a product. Achieving effective water quality protection is not designed without the organization of a surveillance and control system. Currently, the effectiveness of such national surveillance systems is closely linked to automatic water quality control equipment. Tap water and bottled water must be safe for human consumption and their parameters must comply with legal requirements in order to be delivered to consumers and not pose a threat to human health. In this context, in order to carry out an experimental study on improving water quality, have been applied the two methods, Taguchi's method and the factorial experiment method, in order to highlight the deficiencies of the water treatment process in order to be able to water it, the help of the two methods would be very difficult to identify, given that there is a large amount of data for analysis. Both methods have been a real help in finding solutions to achieve the desired results at the end of the water drinking process. Monitoring the four relevant steps in the process is now much easier because at the moment, due to the application of the two methods, the values that need to be followed are settled. The optimization of the water treatment process has been done to help both the treatment plant and the consumers that depend directly and implicitly on it. This optimization is to avoid situations in which the station may be unable to cover the required volume of drinking water, as well as the use of existing and used best practices in a structured and systematic way. This process satisfies customer requirements and auditing, as well as its own need to prevent failures. Water quality protection is a permanent action in which each member of society has to make its contribution, a conscious and responsible contribution. Water is of particular importance for human, plant and animal life, and is an indispensable component of life. For all the above reasons, any water treatment plant is aware of its great responsibility towards consumers and many others, and the guarantee of the quality of drinking water that is constantly and permanently supplied to us at any time will be always the main objective to achieve.

\section{References}

1. $* * *$ World water balance and water resources of Earth, UNESCO, Paris (1978)

2. S. Mănescu, Environmental Hygiene (in Romanian), (Medical Publishing House, București, 1981)

3. L. Oprean, Water - The Fundamental Resource of Sustainable Development: Methods and Techniques Unconventional Water Purification and Treatment (in Romanian), I, Romanian Academy Publishing House, București, 25, (2012)

4. ***mmediu.ro - Ministry of Environment, Water and Forests, 02.08.2017

5. A. Ghobadian, S. Speller, „Total Quality Management" 5, no. 4, 53-69 (1994)

6. R. K. Roy, A primer on the Taguchi method (Van Nostrand Reinhold, New York, 1990)

7. M. Țîţu, C. Oprean., A. Boroiu., Experimental Research Applied in Increasing Quality Products and Services (in Romanian), (AGIR Publishing House, București, 2011)

8. D. Montgomery, Design and Analysis of Experiments. Eighth Edition (Hoboken: John Wiley \& Sons, Inc., 2013) 